Article

\title{
Contamination, Spatial Distribution and Source Analysis of Heavy Metals in Surface Soil of Anhui Chaohu Economic Development Zone, China
}

\author{
Chang Pan ${ }^{1}\left(\right.$, Fei Yu ${ }^{2}$, Xiao Tao ${ }^{3}$, Jiahuan Guo ${ }^{1}$ and Yuanchun $\mathrm{Yu}^{1, *(1)}$ \\ 1 Co-Innovation Center for Sustainable Forestry in Southern China, College of Biology and the Environment, \\ Nanjing Forestry University, Nanjing 210037, China; panchang2020@163.com (C.P.); \\ guojiahuan2018@163.com (J.G.) \\ 2 Jiangsu Polytechnic College of Agriculture and Forestry, Jurong 212400, China; feiyunj@163.com \\ 3 College of Forestry and Landscape Architecture, Anhui Agricultural University, Hefei 230036, China; \\ hyytaoxiao@163.com \\ * Correspondence: ycyu@njfu.edu.cn; Tel.: +86-25-8542881
}

Received: 3 September 2020; Accepted: 28 September 2020; Published: 1 October 2020

\begin{abstract}
Anthropogenic activities may result in the accumulation of heavy metals in the soil, especially in economic development zones with frequent industrial activities. Therefore, the investigation and assessment of soil heavy metal pollution in economic development zones is one of the important measures for soil environmental management and sustainable development. This study used Nemero evaluation, Kriging interpolation, cluster analysis, and principal component analysis to investigate the contamination degree, spatial distribution, and origin of heavy metal in Anhui Chaohu Economic Development Zone (ACED), Anhui, East China. The result showed that different land use types can cause different levels and types of soil heavy metal pollution. The maximum concentrations of heavy metals in the study area all exceeded their background value but did not exceed the guide values. The highest average concentrations were found in $\mathrm{Zn}$, followed by $\mathrm{Cr}$ and Ni. The concentrations of As in soils have the largest coefficient of variation $(\mathrm{CV})$ at $38 \%$. The concentration of heavy metals in different functional areas was varied, the areas with higher $\mathrm{Ni}, \mathrm{As}, \mathrm{Cd}, \mathrm{Zn}$, and $\mathrm{Cr}$ concentrations were mainly distributed in Hot Springs Resort (HSR), the relatively higher concentrations of $\mathrm{Pb}$, $\mathrm{Hg}$, and $\mathrm{Cu}$ were mainly distributed in Integrated Zone (IZ), while all heavy metal (except for $\mathrm{Ni}$ ) have relatively higher content in the surface soil of Huashan Industrial Zone (HIZ). Origin analysis showed that soil As, Cd, and Zn in HSR surface soil were predominantly influenced by agricultural activities, while $\mathrm{Ni}$ and $\mathrm{Cr}$ were mainly controlled by parent material. $\mathrm{Pb}$ and $\mathrm{Hg}$ in $\mathrm{IZ}$ surface soil were predominantly originated from the vehicle and domestic exhaust, and $\mathrm{Cu}$ was mainly controlled by industrial pollutants. Industrial activity was the main source of soil heavy metals in HIZ. Although heavy metal in ACED surface soil did not reach pollution levels, the concentration of $\mathrm{Cd}, \mathrm{Hg}, \mathrm{Pb}$, and $\mathrm{Cu}$ was significantly affected by anthropogenic activities, especially in $\mathrm{HIZ}$, which the necessary attention of heavy metals needs to be given.
\end{abstract}

Keywords: soil contamination; industrial area; urban soil; pollution assessment; topsoil

\section{Introduction}

It is well known that the soil heavy metal pollution may lead to various diseases to humans through the food chain and suspended dust [1]. Therefore, heavy metal pollution in the soil has been a large concern for people. Heavy metals in soil mainly come from parent materials and anthropogenic activities [2-4]. However, in the past several decades, with the development of industrialization and urbanization, anthropogenic activities such as coal-burning, metallurgy, mining, vehicular emissions, 
and agricultural activities have become major contributors to the accumulation of heavy metals in soils [5-7]. As a result, soil heavy metal pollution has grown to be a major environmental problem in China, especially in the industrial and mining areas [8,9].

Urbanization and industrialization are often accompanied by changes in the types of land use, which increase the impact of human activities on the heavy metals in the soil, resulting in the accumulation and even pollution of heavy metals in the soil [10]. In China, the economic development zone plays an important role in the Chinese economy. In the past 40 years, countless economic development zones have been set up throughout the country. Until the end of 2018, 219 national economic development zones have been established. However, although economic development zones have brought economic progress, they have also brought various environmental problems such as air, water, and soil pollution [11]. Among them, the problem of soil heavy metal pollution in economic development zones has not received due attention for a long time in China [12,13].

In many cases, China's economic development zone is not just an industrial zone. It often contains multiple functional zones such as industry, residential, commerce, and so on. Therefore, the concentration of heavy metals in economic development zone soils can be influenced by many factors, such as domestic waste, industrial emissions, building materials, automobile exhaust, and parent materials [14-17]. Owing to the complexity of heavy metal pollution in economic development zones, the determination of heavy metal content, pollution status, spatial distribution, and origin has become very important for environmental protection and governance.

There are numerous studies on the contamination assessment, spatial distribution analysis, and source identification of soil heavy metal pollution $[11,18,19]$. The generally used method for the source identification of soil heavy metal pollution is multivariate statistics such as principal component analysis, cluster analysis, and person correlation analysis [20-22]. Kriging is also a typical method for obtaining maps of heavy metal spatial distribution and combined with multivariate statistics to aid in pollution assessment and source identification [23-25]. Moreover, the assessment of heavy metal pollution is also of serious concern. There are many methods for evaluating soil pollution. Among them, Nemero index, Geo-accumulation index, and Health Risk Assessment are widely used assessment methods [26,27].

In recent years, scholars have made great achievements in heavy metal pollution assessment and pollution source identification [28-30]. However, most research has focused on the industrial and mining sectors, and economic development zones with diverse land use types have received less attention. Due to the diversity of soil heavy metal pollution sources in economic development zones, heavy metal may have a different concentration, and spatial distribution characteristics. Therefore, analysis of the source, concentration and spatial distribution characteristics of heavy metal is one of the important prerequisites for controlling heavy metal pollution.

As a typical national economic development zone in eastern China, Anhui Chaohu's economic development zone (ACED) was established in 1995. However, the characteristics of soil heavy metals in ACED surface soil are still unknown. Since the development zone contains many metal processing enterprises, roads, and residential areas, the potential soil heavy metal pollution in ACED cannot be ignored. Therefore, the investigation of soil heavy metal in development zones has become essential. Consequently, the purpose of this study were: (1) Analyzing the content and spatial distribution of heavy metals in the surface soil of ACED; (2) determining the pollution degree and origin of heavy metals in ACED; (3) providing the basis for the prevention and control of soil heavy metal pollution in economic development zones in China.

\section{Materials and Methods}

\subsection{Study Area}

Anhui Chaohu economic development Zone (ACED) is one of the major economic development zones in Hefei, located in the middle of Anhui province $\left(31.64^{\circ} \mathrm{N}, 117.92^{\circ} \mathrm{E}\right)$, and covers total terrestrial 
areas of $61 \mathrm{~km}^{2}$. ACED has been an area dominated by industry for about 25 years, which is mainly divided into Huashan Industrial Zone (HIZ), Hot Springs Resort (HSR), and Integrated Zone (IZ). HIZ is located in the east of the ACED, and contains a lot of enterprises such as foundries, electroplating factories, battery manufacturing plants, and steel cable factories that may discharge heavy metal into the surrounding environment. IZ is situated on the west of ACED, with both enterprises and residential areas, and these enterprises are mostly engaged in metal manufacturing. The northern part of the ACED is HSR, mainly used for agricultural activities and tourism development. In order to determine the characteristics of heavy metal pollution between different regions, Nemerow index was used to evaluate the pollution level of ACED according to the national guide value of soil (GB15618-2018 for $\mathrm{Zn}$ and $\mathrm{GB}$ 36600-2018 for $\mathrm{Cu}, \mathrm{Hg}, \mathrm{Pb}, \mathrm{Ni}, \mathrm{Cd}, \mathrm{Cr}$ and $\mathrm{As}$ ). Figure 1 illustrates the fundamental information of ACED.

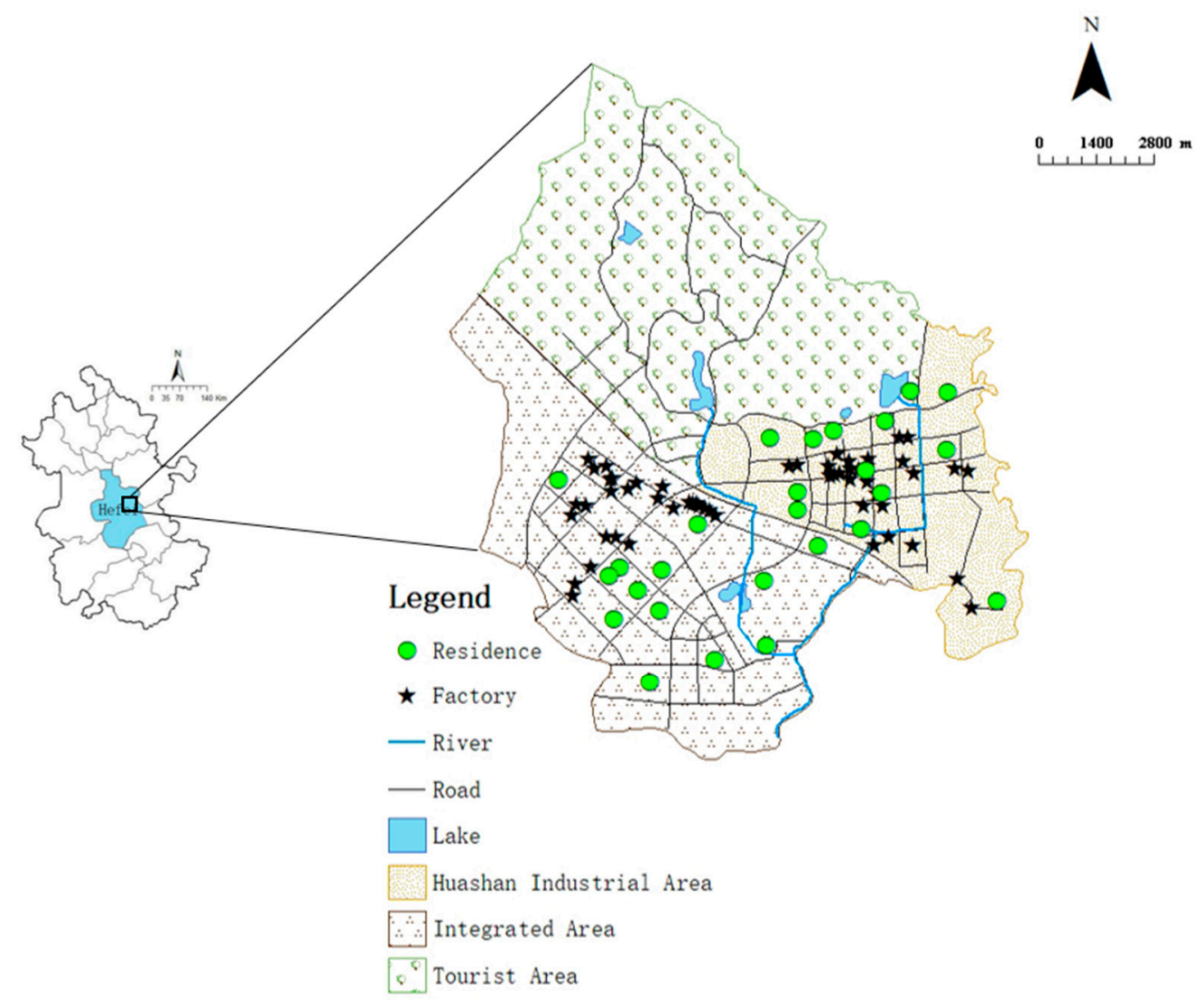

Figure 1. Geographical location and division of major functional areas of Anhui Chaohu economic development Zone.

\subsection{Sampling}

Soil sampling was carried out in July 2017. The systematic grid sampling method was adopted. A total of 63 samples were selected from ACED (Figure 2). The distance between each sampling point was about $1000 \mathrm{~m}$ and adjusted according to the actual terrain. The five-point sampling method was adopted, the distance between each sub-sample was about $1 \mathrm{~m}$, and the sampling depth was $0-20 \mathrm{~cm}$, and then five sub-samples were mixed thoroughly to obtain a sample at the sampling point. All samples were stored in polyester plastic bags and air-dried after removal of stone, sticks, and other debris. After appropriate air-drying, samples were powdered and sieved using a 100-mesh nylon sieve. Determination of $\mathrm{Cu}, \mathrm{Cr}, \mathrm{Cd}, \mathrm{Ni}, \mathrm{Pb}$ and $\mathrm{Zn}$ by using inductively coupled plasma mass spectrometry (ICP-MS), while $\mathrm{Hg}$ and As were determined using apply atomic 
fluorospectro-photometer. The collected soil samples were determined in accordance with the national standard (GB 15618-2018 for Zn and GB 36600-2018 for other heavy metals).

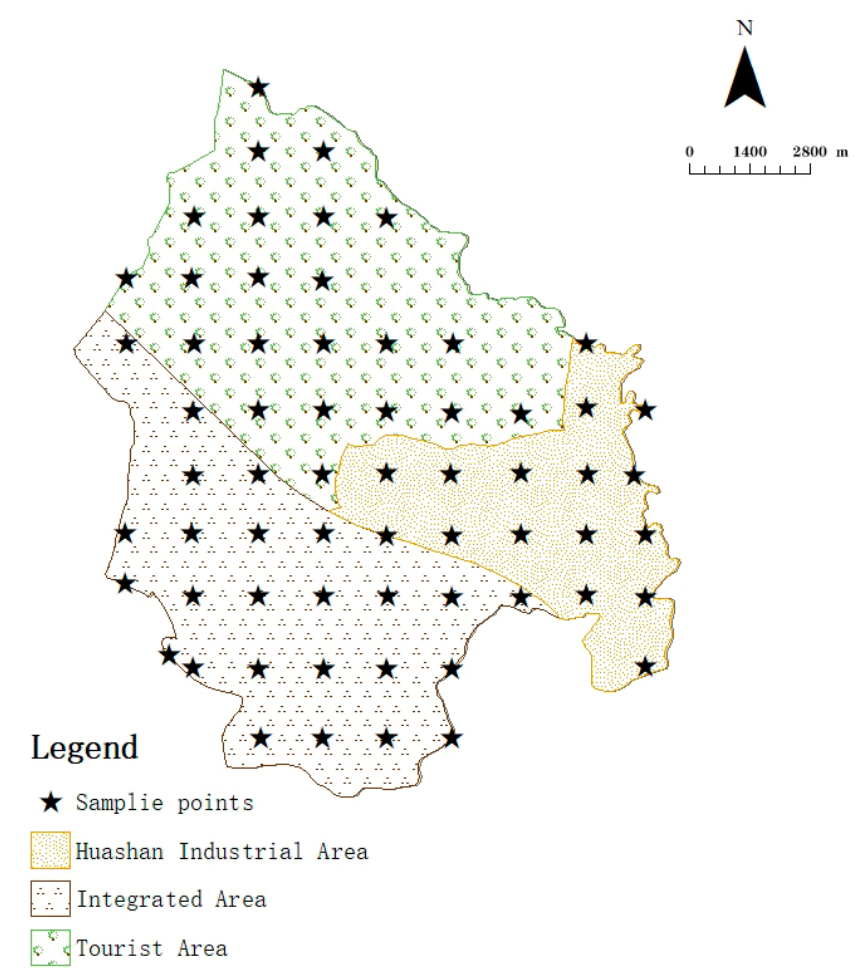

Figure 2. Distribution of sample points in study area.

\subsection{Statistical Analysis}

Before statistical analysis, the raw data were tested by triplex standard deviation, the test results show that there was no abnormal value. Multivariate statistical analysis including principal component analysis (PCA), cluster analysis (CA), and Pearson correlation analysis was carried out by using SPSS 22 software. ANOVA was used to determine the difference in heavy metal concentration between different regions.

Ordinary Kriging interpolation was performed (using of ArcGIS 10.0) to gain the spatial distribution of heavy metals in ACED topsoil. Before Kriging interpolation, Kolmogrov-Simirnow test (K-S test) was performed to determine whether the raw data have a normal distribution (using of SSPS 22). According to the result of K-S test, Logarithm transformation was performed on the data of $\mathrm{Cu}, \mathrm{Ni}, \mathrm{Pb}$, As, and square root transformation was performed on the data of $\mathrm{Cd}$ and $\mathrm{Hg}$ to obtain heavy metal data with normal distribution (the original data of $\mathrm{Cr}$ and $\mathrm{Zn}$ were in accordance with the normal distribution, no conversion was required). After transformation, Ordinary Kriging interpolation was executed.

\subsection{Pollution Assessment}

According to the national guide value of soil (GB15618-2018 for Zn and GB 36600-2018 for Cu, $\mathrm{Hg}$, $\mathrm{Pb}, \mathrm{Ni}, \mathrm{Cd}, \mathrm{Cr}$ and $\mathrm{As}$ ), the Nemerow pollution index method was used to assess the degree of soil heavy metal pollution in the study area. The formula is as follows [31]:

$$
\begin{gathered}
P_{i}=\frac{C_{i}}{S_{i}} \\
\bar{p}=\frac{1}{2} \sum_{i=1}^{\mathrm{n}} \frac{C_{i}}{S_{i}}
\end{gathered}
$$




$$
P_{c}=\sqrt{\frac{\operatorname{MaxP}_{i}^{2}+\bar{P}^{2}}{2}}
$$

where $P_{c}$ is Nemero pollution index, $P_{i}$ is the over-limit ratio of the heavy metals in surface soil of the study area, $C_{i}$ is the single heavy metal concentration in surface soil of the study area, and $S_{i}$ is the guide value of heavy metals in Chinese Environmental Quality Standard for Soils (GB 36600-2018 and GB15618-2018, Table 1). According to the Nemerow index evaluation method, $P_{c}$ values less than 1 are considered uncontaminated, and $P_{c}$ values greater than or equal to 1 are considered contaminated. A larger $P_{c}$ value represents a more serious pollution situation [32]. 
Table 1. Eight heavy metal concentrations in the study area $\left(\mathrm{mg} \cdot \mathrm{kg}^{-1}\right) \cdot \mathrm{CV}=$ coefficient of variation. Different lowercase letters on the same line indicate significant differences $(p<0.05)$

\begin{tabular}{|c|c|c|c|c|c|c|c|c|c|c|c|c|c|}
\hline \multirow{2}{*}{ Species } & \multirow{2}{*}{$\begin{array}{c}\text { Mean } \\
(\mathrm{n}=63)\end{array}$} & \multicolumn{3}{|c|}{ HSR $(n=22)$} & \multicolumn{3}{|c|}{ IZ $(n=26)$} & \multicolumn{3}{|c|}{ HIZ ( $n=15)$} & \multirow{2}{*}{$\begin{array}{c}\text { Background } \\
\text { Value [33] }\end{array}$} & \multirow{2}{*}{$\begin{array}{c}\text { Guide } \\
\text { Value } 1\end{array}$} & \multirow{2}{*}{ CV (\%) } \\
\hline & & Mean & Minimum & Maximum & Mean & Minimum & Maximum & Mean & Minimum & Maximum & & & \\
\hline $\mathrm{Cu}$ & 33.7 & $33.409 \pm 1.75 a$ & 21.6 & 46.3 & $33.162 \pm 1.74 a$ & 20.9 & 49.6 & $34.9 \pm 2.17 \mathrm{a}$ & 20.5 & 46.1 & 24.9 & 18000 & 25.036 \\
\hline $\mathrm{Zn}$ & 166.8 & $166.545 \pm 5.40 a$ & 117 & 207 & $166.5 \pm 6.44 a$ & 110 & 216 & $167.533 \pm 6.88 \mathrm{a}$ & 120 & 219 & 53.2 & 250 & 17.087 \\
\hline $\mathrm{Cr}$ & 62.6 & $62.195 \pm 2.66 a$ & 40.8 & 83.4 & $65.812 \pm 2.91 \mathrm{a}$ & 40.4 & 90 & $57.78 \pm 3.04 a$ & 40 & 84.1 & 69.4 & 200 & 21.603 \\
\hline $\mathrm{Ni}$ & 36.2 & $40.359 \pm 2.77 a$ & 15.7 & 54.6 & $32.592 \pm 2.14 b$ & 17.2 & 50.5 & $36.5 \pm 2.75 a$ & 16.2 & 52.5 & 25 & 900 & 32.952 \\
\hline $\mathrm{Cd}$ & 0.242 & $0.247 \pm 0.01 \mathrm{a}$ & 0.163 & 0.346 & $0.231 \pm 0.01 \mathrm{a}$ & 0.155 & 0.337 & $0.255 \pm 0.02 a$ & 0.157 & 0.346 & 0.104 & 65 & 25.44 \\
\hline $\mathrm{Pb}$ & 34.2 & $34.682 \pm 1.88 \mathrm{a}$ & 20.3 & 49.9 & $33.915 \pm 1.72 \mathrm{a}$ & 20.3 & 48.6 & $33.94 \pm 2.23 a$ & 20 & 47.7 & 25.9 & 800 & 25.236 \\
\hline $\mathrm{Hg}$ & 0.268 & $0.25 \pm 0.19 a$ & 0.112 & 0.39 & $0.27 \pm 0.16 \mathrm{a}$ & 0.114 & 0.391 & $0.293 \pm 0.22 \mathrm{a}$ & 0.137 & 0.399 & 0.041 & 38 & 32.256 \\
\hline As & 11.3 & $11.724 \pm 0.98 \mathrm{a}$ & 5.01 & 19.3 & $10.419 \pm 0.83 a$ & 5.43 & 19.02 & $12.203 \pm 1.12 \mathrm{a}$ & 5.28 & 19.78 & 9.4 & 60 & 38.735 \\
\hline
\end{tabular}

${ }^{1}$ Chinese Environmental Quality Standard for Soils (GB15618-2018 for Zn and GB 36600-2018 for other heavy metals) of $6.5<\mathrm{pH} \leq 7.5$. 


\section{Results}

\subsection{Heavy Metal Concentration Characteristics in the Study Area}

A descriptive summary of heavy metal measures are presented in Table 1. The maximum concentrations of eight heavy metals in the study area all exceeded their background value and the minimum value of $\mathrm{Zn}, \mathrm{Hg}$, and $\mathrm{Cr}$ exceeded their background values respectively. The highest average concentrations were observed for $\mathrm{Zn}$, followed by $\mathrm{Cr}$ and $\mathrm{Ni}$. The areas with a relatively higher mean value of all heavy metal was mainly observed in HIZ and concentrations of soil heavy metal in HSR and IZ are lower than in HIZ. The concentrations of As in soil varied greatly, ranging from 5.01 to $19.78 \mathrm{mg} \cdot \mathrm{kg}^{-1}$, with the largest coefficient of variation $(\mathrm{CV})$ at $38.735 \%$. The maximum concentration of $\mathrm{Hg}$ was approximately ten times as the background value. Although the maximum concentrations of eight heavy metals in the study area exceeded their background values, they did not exceed the guide values. The content of $\mathrm{Ni}$ in IZ is significantly lower than that in other regions, and the distribution of heavy metals in other regions has no significant differences between different regions.

\subsection{Correlation Analysis of Heavy Metals in the Study Area}

Pearson correlation coefficients between eight heavy metals are presented in Table 2. The degree of relationship between two variables can provide information on sources of heavy metal. The results show that the correlation coefficients of As-Zn and As-Cd are 0.259, $0.300(p<0.05)$ respectively, which were positively correlated, the correlation coefficients of $\mathrm{Ni}$ and $\mathrm{Cu}$ are $-0.286(p<0.05)$ which were negative correlated, and the correlation coefficients of other heavy metals have a smaller correlation coefficient $(p<0.05)$.

Table 2. Pearson correlation coefficients between heavy metals in the study area.

\begin{tabular}{ccccccccc}
\hline & $\mathbf{C u}$ & $\mathbf{Z n}$ & $\mathbf{C r}$ & $\mathbf{N i}$ & $\mathbf{C d}$ & $\mathbf{P b}$ & $\mathbf{H g}$ & $\mathbf{A s}$ \\
\hline $\mathrm{Cu}$ & 1 & & & & & & & \\
$\mathrm{Zn}$ & 0.242 & 1 & & & & & & \\
$\mathrm{Cr}$ & -0.209 & 0.06 & 1 & & & & & \\
$\mathrm{Ni}$ & $-0.286 *$ & -0.041 & -0.128 & 1 & & & \\
$\mathrm{Cd}$ & -0.074 & 0.004 & -0.197 & 0.014 & 1 & 1 & & \\
$\mathrm{~Pb}$ & 0.097 & -0.141 & -0.045 & -0.073 & 0.052 & 1 & \\
$\mathrm{Hg}$ & -0.119 & -0.149 & -0.059 & -0.196 & -0.059 & 0.095 & 1 & \\
$\mathrm{As}$ & -0.047 & $0.259 *$ & -0.069 & 0.057 & 0.300 * & 0.081 & 0.058 & 1 \\
\hline \multicolumn{7}{c}{${ }^{*}$ Correlation is significant at 0.05 (two-tailed). }
\end{tabular}

\subsection{Principal Component Analysis of Heavy Metals in the Study Area}

There are four components with eigenvalues greater than unity, so those four components were obtained and listed in Table 3. The principal components 1 (PC1) explains $18.45 \%$ of the variance and is composed by $\mathrm{Zn}, \mathrm{Cd}$, and As. The PC2 explains $17.5 \%$ of the variance and is only composed of Ni. The PC3 explains $16.49 \%$ of the variance and is composed by $\mathrm{Pb}$ and $\mathrm{Hg}$. The PC4 explains $13.99 \%$ of the variance and is composed of $\mathrm{Cr}, \mathrm{Hg}$, and As. 
Table 3. Principle component analysis for heavy metals in the study area.

\begin{tabular}{ccccc}
\hline Component & PC1 & PC2 & PC3 & PC4 \\
\hline $\mathrm{Cu}$ & 0.239 & -0.547 & 0.031 & -0.315 \\
$\mathrm{Zn}$ & 0.362 & -0.253 & -0.375 & 0.266 \\
$\mathrm{Cr}$ & -0.290 & -0.072 & -0.246 & 0.591 \\
$\mathrm{Ni}$ & 0.011 & 0.481 & -0.273 & -0.306 \\
$\mathrm{Cd}$ & 0.406 & 0.281 & 0.161 & 0.022 \\
$\mathrm{~Pb}$ & 0.067 & -0.049 & 0.458 & -0.046 \\
$\mathrm{Hg}$ & -0.122 & 0.006 & 0.493 & 0.341 \\
$\mathrm{As}$ & 0.470 & 0.183 & 0.052 & 0.403 \\
$\%$ of variance & 18.45 & 17.50 & 16.49 & 13.99 \\
$\%$ of cumulative & 18.45 & 35.95 & 52.44 & 66.43 \\
\hline
\end{tabular}

\subsection{Cluster Analysis of Heavy Metals in the Study Area}

The results of the cluster analysis show that eight heavy metals were divided into five categories (Figure 3). The first group contains $\mathrm{Cd}$ and As. The second group contains $\mathrm{Cu}$ and $\mathrm{Zn}$. The third group consists of $\mathrm{Pb}$ and $\mathrm{Hg}$. The fourth and the fifth group were $\mathrm{Cr}$ and Ni respectively. Among them, the distance between $\mathrm{Cd}$, and As was the smallest, followed by $\mathrm{Cu}-\mathrm{Zn}$ and $\mathrm{Pb}-\mathrm{Hg}$, and the distance between $\mathrm{Cr}$ and $\mathrm{Ni}$ and other heavy metals was the largest.

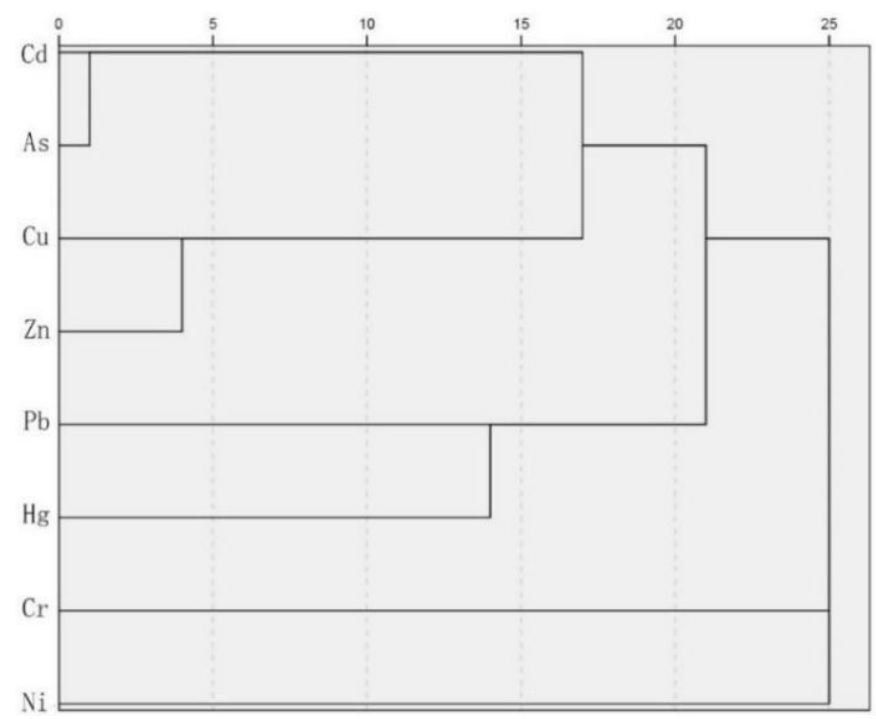

Figure 3. Dendrogram of cluster analysis of eight heavy metals in Anhui Chaohu economic development Zone. The distance between heavy metals indicates the correlation between heavy metals, and the close distance indicates a large correlation.

\subsection{Evaluation of Heavy Metal Pollution in the Study Area}

Class II guide values of $\mathrm{Cu}, \mathrm{Pb}, \mathrm{As}, \mathrm{Cd}, \mathrm{Ni}, \mathrm{Cr}$, and $\mathrm{Hg}$ in Chinese Environmental Quality Standard for Soils (GB 36600-2018) and Zn in GB15618-2018 was adopted (Table 1), the comprehensive pollution indexes of heavy metals in the study area were calculated. Results of Nemero evaluation show that the heavy metal content of the soil in the study area were within the clean range (Figure 4). Although there was no statistical difference in $P_{c}$ values between different regions, the $P_{c}$ values of soil heavy metals were different in different regions, the maximum value of $P_{c}$ in HSR, IZ, and HIZ was 0.603, 0.616 , and 0.632 respectively, and the overall $P_{c}$ value varied in the order: HIZ $>$ HSR $>$ IZ. Moreover, $P_{c}$ value changes the most in IZ, while HSR and HIZ have smaller changes. 


\subsection{Spacial Analysis of Heavy Metals in the Study Area}

As shows in Figure 5, the distribution of heavy metals in the study area varies greatly with the different types of heavy metals. The regions with high concentration of As and Cd were HSR, followed by HIZ and IZ. On the contrary, the distribution of $\mathrm{Cu}$ and $\mathrm{Pb}$ was mainly concentrated in IZ. Interestingly, Ni shows a strong trend of enrichment in HSR, while Hg presents a higher concentration in IZ but rarely in HSR. The distribution of $\mathrm{Zn}$ was relatively uniform, and the high concentration areas are mainly allocated in HIZ and HSR. Although Cr was mainly concentrated in HSR and IZ, the distribution of $\mathrm{Cr}$ was continuous between different regions, which was quite different from the distribution of other heavy metals.

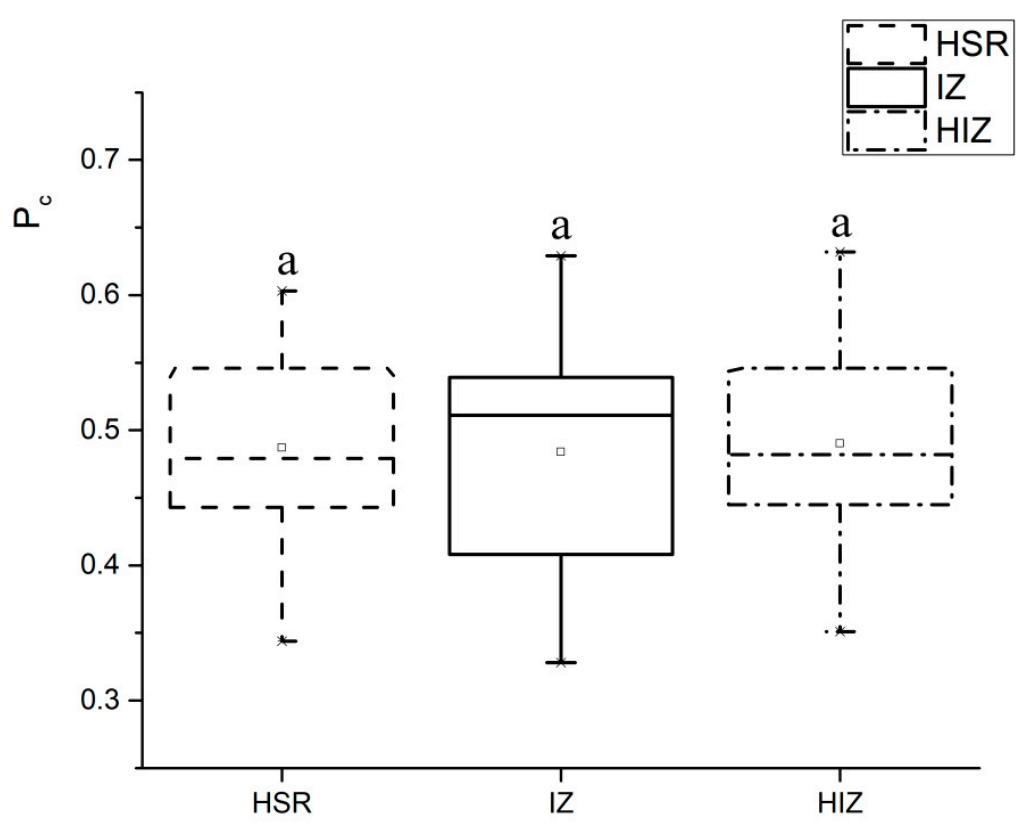

Figure 4. Results of Nemero evaluation of heavy metal content in soils in Anhui Chaohu economic development Zone. HIZ = Huashan Industrial Zone, HSR = Hot Springs Resort, IZ = Integrated Zone, $P_{c}=$ Nemero pollution index. The lines above and below the box indicate the maximum and minimum values, the upper and lower edges of the box indicate the upper and lower quartiles, and the line inside the box indicates the median the same lowercase letters indicate no significant difference $(p<0.05)$. 


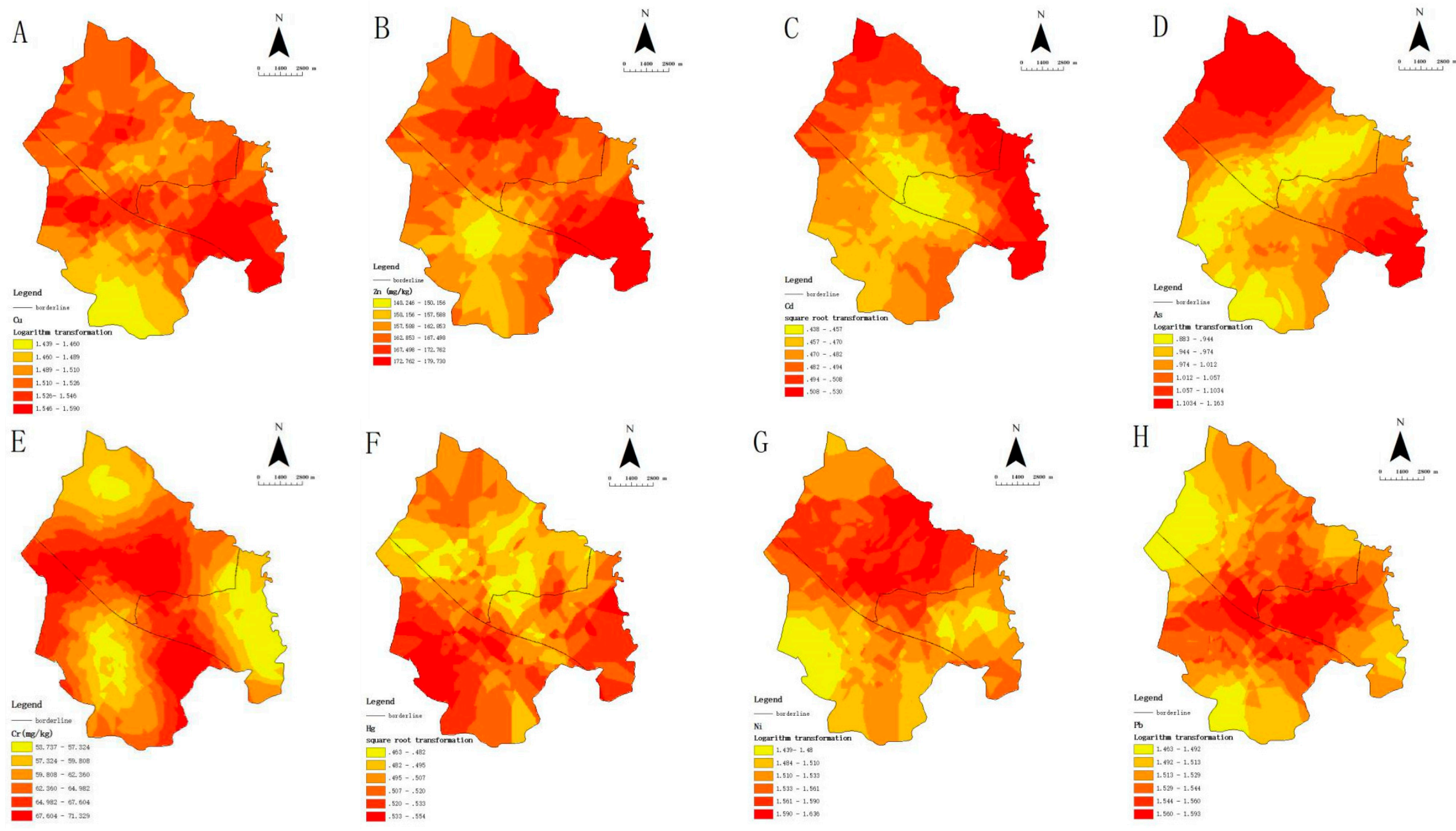

Figure 5. Spatial distribution of heavy metals in Anhui Chaohu economic development Zone. The boundary line refers to the boundary between HSR, IZ and $\mathrm{HIZ}$. The data used for graph drawing of $\mathrm{Ni}$ and $\mathrm{Zn}$ were original data $\mathrm{Cu}, \mathrm{Ni}, \mathrm{Pb}$, As were logarithmic conversion, and $\mathrm{Cd}$ and $\mathrm{Hg}$ were square root conversion. (A-H) represent $\mathrm{Cu}, \mathrm{Zn}, \mathrm{Cd}, \mathrm{As}, \mathrm{Cr}, \mathrm{Hg}, \mathrm{Ni}$ and $\mathrm{Pb}$ respectively. 


\section{Discussion}

\subsection{The Characteristics of Heavy Metals in HSR Surface Soil}

Anthropogenic activities are one of the main factors for the accumulation of heavy metals in the soil. With the development of the economy in china, a large amount of arable land has been used for industrial production or tourism development, which increases the possibility of soil contamination by heavy metals.

HSR has long been used as agricultural land in history. At present, HSR has been developed as a tourist area, with a large number of hot spring hotels, wetlands, and artificial landscapes. Depending on the results of spatial analysis (Figure 5), the areas with higher Ni, As, Cd Zn, and Cr concentration are mainly distributed in HSR. The mean value of Ni, As, Cd Zn, and $\mathrm{Cr}$ in HSR were observed higher than other studies on agricultural soils [34,35], but lower than studies on industrial soils [11], indicating that anthropogenic activities may have resulted in the accumulation of heavy metals during historical and current. Although heavy metal in the HSR surface soil did not reach the pollution level (Figure 4), their content increased to varying degrees relative to the background value (Table 1), indicating that there are still external factors affecting the concentration of heavy metal in the HSR surface soil.

Previous surveys expounded that the influence of anthropogenic activities on the soil concentrations of $\mathrm{Ni}$ and $\mathrm{Cr}$ are low [18,36], and $\mathrm{Ni}$ can be transferred into the soil through hot springs [27,37]. In this study, there are many hot springs in HSR. In addition, according to PCA analysis, the PC2 explains 17.5\% of the variance and only composed by Ni (Table.3), indicating that the source of $\mathrm{Ni}$ in HSR maybe parent materials, reiterated the other researches $[27,38]$. The concentration of $\mathrm{Cr}$ in the study area surface soil with a smaller CV of $21.603 \%$, and low correlation with other elements (Table 2), indicating that $\mathrm{Cr}$ was affected by relatively minor anthropogenic activities. Depending on the results of the cluster and spatial analysis (Figures 3 and 5), $\mathrm{Cr}$ and Ni were classified into one category, but have the largest distance, indicating that, the main source of Cr in HSR may be the parent materials.

Numerous researchers have suggested that soil contaminated by As and Cd can be attributed to human agriculture activities such as the use of agrochemical, phosphate fertilizers and industrial metallurgy $[15,35,39]$. In this study, the high correlation between Cd and As was observed (Table 2), and consistent with the results of CA (Figure 3), indicating that $\mathrm{Cd}$ and As may originate from the same source. According to the results of the spatial analysis, the areas with a high concentration of $\mathrm{Cd}$ and As were mainly distributed in HSR (Figure 5), illustrating that Cd and As in HSR may come from agricultural activities. The areas with a high concentration of $\mathrm{Pb} \mathrm{Zn}$ were also mainly distributed in HSR (Figure 5), indicating that $\mathrm{Zn}$ in the soil of the study area may come from agricultural activities partly, because the use of zinc-containing pesticides may lead to accumulation of $\mathrm{Zn}$ in the soil [40], this also explains why As, Cd and Zn composed the PC1 in PCA and the correlation coefficients of As-Zn is a positive correlation $(0.259, p<0.05)$.

Generally, heavy metals in HSR surface soil did not reach the pollution level. However, because the accumulation of heavy metals has been observed, necessary measures must be given to protect the soil in HSR from further heavy metal enrichment.

\subsection{The Characteristics of Heavy Metals in HIZ Surface Soil}

As the most important economic part of ACED, HIZ is concentrated in many enterprises, including metal processing, metal smelting, and other enterprise types, which may lead to changes in soil heavy metal concentrations. In this study, the concentration of heavy metals in HIZ was generally higher than other industrial land in China [9,11,36], but lower than an industrial zone in Mexico [41] and in India (except for $\mathrm{Zn}$ ) [12]. Depending on the results of spatial analysis and Nemero evaluation (Figures 4 and 5), although heavy metals in the surface soil of HIZ did not reach pollution levels, the higher heavy metals concentration (except for Ni) in HIZ surface soil were observed, indicating that heavy metals in HIZ surface soil may be affected by relatively intensive anthropogenic activities. 
Many researchers have suggested that anthropogenic activities such as improper disposal of electrical conducts and combustion of fossil fuels as well as industrial activities can release $\mathrm{Hg}$ into the environment $[11,25,27,41]$. The concentration of $\mathrm{Pb}$ in soil are associated with anthropogenic activities such as the pharmaceutical, battery manufacturing, and waste incineration [11,39], and the traffic is most possibly the major source for the enrichment of $\mathrm{Pb}$ in the soils [35].

According to the PCA and CA analysis results, $\mathrm{Pb}$ and $\mathrm{Hg}$ were classified into one category (Table 3 and Figure 3), indicating that $\mathrm{Pb}$ and $\mathrm{Hg}$ may originate from the same source. Depending on the results of spatial analysis (Figure 5), the areas with a high concentration of $\mathrm{Pb}$ were close to a battery plant and main road, indicating that the concentration of $\mathrm{Pb}$ in $\mathrm{HIZ}$ was mainly influenced by pollutants released from industrial production and transportation, consistent with previous research [11,35].

Soil contaminated by As and Cd can be attributed to agricultural and industrial activities [33,39]. However, there was almost no agricultural activity in HIZ and the concentration of As in IZ and HIZ were lower than in HSR, indicating that the soil As and Cd in HIZ were mainly influenced by anthropogenic activities such as the foundry's longtime burning of coal [15]. Releases of $\mathrm{Cu}$ and $\mathrm{Zn}$ from anthropogenic activities is mainly include building materials and metal processing industries $[15,18,19,42]$. In this study, the regions with a high concentration of $\mathrm{Cu}$ and $\mathrm{Zn}$ were mainly distributed in HIZ. Therefore, industrial pollutants produced by companies engaged in metal manufacturing in HIZ were likely to be the source of $\mathrm{Cu}$ and $\mathrm{Zn}$ in HIZ.

Consequently, industrial activities have had a significant impact on soil heavy metals in HIZ, and the trend of heavy metal enrichment was more obvious than in other regions. Therefore, it is necessary to prevent the further accumulation of heavy metals in the soil of HIZ.

\subsection{The Characteristics of Heavy Metals in IZ Surface Soil}

IZ is mainly composed of residential areas, commercial areas, and some industrial enterprises. Therefore, heavy metals in the surface soil of IZ may be affected by multiple factors and resulting in large differences in soil heavy metal content (Figure 1). This complex land type explains why the Nemero evaluation values has the highest dispersion in IZ soil (Figure 4). Depending on the results of spatial analysis (Figure $5 \mathrm{~A}, \mathrm{~F}, \mathrm{H}$ ), the areas with higher $\mathrm{Pb}, \mathrm{Hg}$, and $\mathrm{Cu}$ concentration in IZ surface soil were observed, which indicates that the content of $\mathrm{Pb}, \mathrm{Hg}$, and $\mathrm{Cu}$ in the surface soil of IZ has been affected by external influences. Although the concentrations of eight heavy metals in IZ soil were significantly higher than the background value, they were lower than other studies in urban soils of China $[43,44]$, suggesting a relatively moderate external influence of soil heavy metals when compared to HIZ.

Anthropogenic activities such as improper disposal of electrical conducts and combustion of fossil fuels as well as industrial activities can release $\mathrm{Hg}$ into the environment $[25,27,41]$. The concentration of $\mathrm{Pb}$ in the soil are associated with anthropogenic activities such as the pharmaceutical, battery manufacturing, and waste incineration [11,39], and the traffic is most possibly the major source for the enrichment of $\mathrm{Pb}$ in the soils [35]. Depending on the results of spatial analysis (Figure 5), different from $\mathrm{HIZ}$, the area with a high concentration of $\mathrm{Pb}$ in IZ was close to the main road, indicating that the concentration of $\mathrm{Pb}$ in IZ may mainly be influenced by transportation, consistent with previous research results [35]. Hg was mainly distributed in residential areas in IZ (Figure 5F), indicating that the main sources of $\mathrm{Hg}$ in IZ may be the vehicle and domestic exhaust [11]. The areas with high $\mathrm{Cu}$ concentration in IZ were concentrated near metal processing enterprises. Therefore, similar to HIZ, $\mathrm{Cu}$ in IZ surface soil may also originated from industrial activities.

Compared with HIZ and HSR, heavy metals in IZ soil were strongly affected by the diversified land use types and frequent human disturbances. Therefore, in the entire study area, human activities, especially industrial production, were the main factors of soil heavy metal enrichment. Although the concentration of heavy metals in the study area has not exceeded the guide value, effective measures must be taken to prevent further heavy metal enrichment. 


\section{Conclusions}

In this study, the concentrations, spatial distribution and sources of $\mathrm{Cu}, \mathrm{As}, \mathrm{Cr}, \mathrm{Ni}, \mathrm{Cd}, \mathrm{Zn}, \mathrm{Hg}$ and $\mathrm{Pb}$ in Anhui Chaohu Economic Development Zone (ACED), surface soil were determined respectively. The preliminary result shows that the maximum concentrations of eight heavy metals in the study area all exceeded their background value but did not exceed the guide values. The results of Nemelo evaluation show that heavy metals in ACED surface soil are at the clean level. The highest average concentrations were observed for $\mathrm{Zn}$, followed by $\mathrm{Cr}$ and $\mathrm{Ni}$. The concentrations of As in soils ranging from 5.01 to $19.78 \mathrm{mg} / \mathrm{kg}$, with the largest coefficient of variation $(\mathrm{CV})$ at $38 \%$.

Distributions of heavy metals in different functional areas were varied, the areas with higher As, $\mathrm{Cd}$ and Ni concentrations were mainly distributed in HSR, while the relatively higher concentrations of $\mathrm{Cr}$ and $\mathrm{Zn}$ were mainly distributed in $\mathrm{HIZ}$ and HSR. The concentration of $\mathrm{Cu}$ and $\mathrm{Pb}$ in different regions was HSR > IZ > HIZ. In addition, IZ soil has the highest $\mathrm{Hg}$ content. Moreover, all heavy metals (except for Ni) have higher content in the surface soil of HIZ. The distribution of heavy metal sources location was uneven and mainly distributed in HIZ and IZ. Further analysis showed that soil Cd, Hg, $\mathrm{Pb}$, and $\mathrm{Cu}$ were predominantly influenced by industrial activities, As were predominantly originated from agricultural activities $\mathrm{Cr}$ and $\mathrm{Ni}$ were mainly controlled by parent material. Consequently, the concentration of $\mathrm{Cd}, \mathrm{Hg}, \mathrm{Pb}$ and $\mathrm{Cu}$ of soil in the study area was significantly affected by anthropogenic activities, especially in HIZ, and the necessary attention of soil heavy metal needs to be given.

Author Contributions: Conceptualization, C.P. and Y.Y.; methodology, C.P.; software, F.Y.; validation, C.P. and Y.Y.; formal analysis, X.T.; investigation, X.T.; resources, J.G.; data curation, J.G.; writing—original draft preparation, C.P.; writing — review and editing, Y.Y.; visualization, F.Y.; supervision, J.G.; project administration, X.T.; funding acquisition, Y.Y. All authors have read and agreed to the published version of the manuscript.

Funding: This research was funded by [The National Natural Science Foundation of China] grant number [31670615, 31700631 and 31270664], and [The Erasmus+ Program of the European Union] grant number [586247-EPP-1-2017-1-IT-EPPKA2- CBHE-JP] and [The Priority Academic Program Development of Jiangsu Higher Education Institutions(PAPD), China].

Conflicts of Interest: The authors declare no conflict of interest.

\section{References}

1. Tepanosyan:, G.; Sahakyan, L.; Belyaeva, O.; Saghatelyan, A. Origin identification and potential ecological risk assessment of potentially toxic inorganic elements in the topsoil of the city of yerevan, armenia. J. Geochem. Explor. 2016, 167, 1-11. [CrossRef]

2. Rodríguez Martín, J.A.; Carbonell, G.; Nanos, N.; Gutiérrez, C. Source identification of soil mercury in the Spanish Islands. Arch. Environ. Contam. Toxicol. 2013, 164, 171-179. [CrossRef] [PubMed]

3. Castillo, S.; Rosa, J.D.; Sánchez, D.; de la Campa, A.M.S.; González-Castanedo, Y.; Fernández-Caliani, J.C.; Gonzalez, I.; Romero, A. Contribution of mine wastes to atmospheric metal deposition in the surrounding area of an abandoned heavily polluted mining district (Rio Tinto mines, Spain). Sci. Total Environ. 2013, 449, 363-372. [CrossRef]

4. Khademi, H.; Gabarrón, M.; Abbaspour, A.; Martínez-Martínez, S.; Faz, A.; Acosta, J.A. Distribution of metal (loid)s in particle size fraction in urban soil and street dust: Influence of population density. Environ. Geochem. Health 2020, 1-4. [CrossRef] [PubMed]

5. Qing, X.; Yutong, Z.; Shenggao, L. Assessment of heavy metal pollution and human health risk in urban soils of steel industrial city (Anshan), Liaoning, northeast China. Ecotoxicol. Environ. Saf. 2015, 120, 377-385. [CrossRef]

6. Pathak, A.K.; Kumar, R.; Kumar, P.; Yadav, S. Sources apportionment and spatio-temporal changes in metal pollution in surface and sub-surface soils of a mixed type industrial area in India. J. Geochem. Explor. 2015, 159, 169-177. [CrossRef]

7. Pace, R.; Liberati, D.; Sconocchia, P.; De Angelis, P. Lead transfer into the vegetation layer growing naturally in a Pb-contaminated site. Environ. Geochem. Health 2019. [CrossRef] 
8. Wei, B.G.; Yang, L.S. A review of heavy metal contaminations in urban soils, urban road dusts and agricultural soils from China. Microchem. J. 2010, 94, 99-107. [CrossRef]

9. He, K.; Sun, Z.; Hu, Y.; Zeng, X.; Yu, Z.; Cheng, H. Comparison of soil heavy metal pollution caused by e-waste recycling activities and traditional industrial operations. Environ. Sci. Pollut. Res. 2017, 24, 1-12. [CrossRef]

10. Li, J.; Pu, L.; Zhu, M.; Liao, Q.; Wang, H.; Cai, F. Spatial pattern of heavy metal concentration in the soil of rapid urbanization area: A case of ehu town, Wuxi city, eastern China. Environ. Earth Sci. 2014, 71, 3355-3362. [CrossRef]

11. Wang, G.Y.; Zhang, S.R.; Xiao, L.Y.; Zhong, Q.M.; Li, L.X.; Xu, G.R.; Deng, O.Q.; Pu, Y.L. Heavy metals in soils from a typical industrial area in Sichuan, China: Spatial distribution, source identification, and ecological risk assessment. Environ. Sci. Pollut. Res. 2017, 24, 1-13. [CrossRef] [PubMed]

12. Li, X.Q.; Meng, D.L.; Li, J.; Yin, H.; Liu, H.; Liu, X.; Liu, Z.; Yan, M. Response of soil microbial communities and microbial interactions to long-term heavy metal contamination. Environ. Pollut. 2017, 231, 908-917. [CrossRef] [PubMed]

13. Xia, W.Y.; Feng, Y.S.; Jin, F.; Zhang, L.M.; Du, Y.J. Stabilization and solidification of a heavy metal contaminated site soil using a hydroxyapatite based binder. Constr. Build. Mater. 2017, 156, 199-207. [CrossRef]

14. Han, Y.; Du, P.; Cao, J.; Eric, S.P. Multivariate analysis of heavy metal contamination in urban dusts of Xi'an, Central China. Sci. Total Environ. 2006, 355, 176-186.

15. Ha, H.; Olson, J.R.; Bian, L.; Rogerson, P.A. Analysis of Heavy Metal Sources in Soil Using Kriging Interpolation on Principal Components. Environ. Sci. Technol. 2014, 48, 4999-5007. [CrossRef]

16. Chen, T.; Chang, Q.R.; Liu, J.; Clevers, J.G.P.W.; Kooistra, L. Identification of soil heavy metal sources and improvement in spatial mapping based on soil spectral information: A case study in northwest China. Sci. Total Environ. 2016, 565, 155-164. [CrossRef]

17. Zhang, J.; Yang, J.; Yu, F.; Liu, X.; Yu, Y. Polycyclic aromatic hydrocarbons in urban Greenland soils of Nanjing, China: Concentration, distribution, sources and potential risks. Environ. Geochem. Health 2020. [CrossRef]

18. Zhou, J.; Feng, K.; Pei, Z.P.; Lu, M.J. Pollution assessment and spatial variation of soil heavy metals in Lixia river region of eastern China. J. Soils Sediments 2016, 16, 748-755. [CrossRef]

19. Lu, C.A.; Zhang, J.F.; Jiang, H.M.; Yang, J.C.; Zhang, J.T.; Wang, J.Z.; Shan, H.X. Assessment of soil contamination with $\mathrm{Cd}, \mathrm{Pb}$ and $\mathrm{Zn}$ and source identification in the area around the huludao zinc plant. J. Hazard. Mater. 2010, 182, 743-748. [CrossRef]

20. Wang, M.G.; Xu, H. A method for identifying the source location of heavy metal pollution in soil. Sci. Technol. Eng. 2012, 18, 4461-4467. (In Chinese)

21. Zhu, W.Q. Location Determination of Land Pollution Source Based on GIS. Softw. Guide 2014, 2, $27-28$. (In Chinese)

22. Zhang, J.; Yu, F.; Pang, S.; Yu, Y. Spatial Distribution and Pollution Assessment of Potentially Toxic Elements in Urban Forest Soil of Nanjing, China. Pol. J. Environ. Stud. 2019, 28, 3015-3024. [CrossRef]

23. Ćujić, M.; Dragović, S.; Đorđević, M.; Dragović, R.; Gajić, B. Environmental assessment of heavy metals around the largest coal fired power plant in Serbia. Catena 2016, 139, 44-52. [CrossRef]

24. Soffianian, A.; Madani, E.S.; Arabi, M. Risk assessment of heavy metal soil pollution through principal components analysis and false color composition in Hamadan Province Iran. Environ. Syst. Res. 2014, 3, 1-14. [CrossRef]

25. Zhou, J.; Feng, K.; Pei, Z.P.; Meng, F.; Sun, J. Multivariate analysis combined with GIS to source identification of heavy metals in soils around an abandoned industrial area, Eastern China. Ecotoxicology 2016, 25, 380-388. [CrossRef]

26. Li, Z.; Ma, Z.; Kuijp, T.; Yuan, Z.; Huang, L. A review of soil heavy metal pollution from mines in China: Pollution and health risk assessment. Sci. Total Environ. 2013, 15, 843-853. [CrossRef]

27. Zhang, Z.Y.; Abuduwailli, J.; Jiang, F.Q. Heavy metal contamination, sources, and pollution assessment of surface water in the Tianshan Mountains of China. Environ. Monit. Assess. 2015. [CrossRef]

28. Saby, N.; Arrouays, D.; Boulonne, L.; Jolivet, C.; Pochot, A. Geostatistical assessment of Pb in soil around Paris, France. Sci. Total Environ. 2006, 367, 212-221. [CrossRef]

29. Cakmak, D.; Perovic, V.; Saljnikov, E.; Jaramaz, D.; Sikiric, B. Spatial modeling of ecological areas by fitting the limiting factors for as in the vicinity of mine, Serbia. Environ. Sci. Pollut. Res. 2014, 21, 3764-3773. [CrossRef] 
30. Krishna, A.K.; Mohan, K.R. Distribution, correlation, ecological and health risk assessment of heavy metal contaminationin surface soils around an industrial area, Hyderabad, India. Environ. Earth Sci. 2016, 75, 411. [CrossRef]

31. Niu, Y.; Zhou, Z.; Huang, D.; Yuan, X. Application of Different Composite Index Methods in the Evaluation of Soil Heavy Metal Pollution. In International Conference on Geo-Informatics in Resource Management and Sustainable Ecosystems; Springer: Singapore, 2017.

32. Zhao, Q.N.; Xu, Q.X.; Yang, K. Application of potential ecological risk index in soil pollution of typical pollution industries. J. East China Norm. Univ. Nat. Sci. 2005, 1, 111-116.

33. Chen, X.R.; Chen, F.R.; Jia, S.J.; Chen, Y.N. Research on the baseline and background values of soil geochemistry in the Changjiang and Huaihe River basins in Anhui Province. Geol. China 2012, 39, 302-310. (In Chinese)

34. Paul, D.; Choudhary, B.; Gupta, T.; Jose, M.T. Spatial distribution and the extent of heavy metal and hexavalent chromium pollution in agricultural soils from Jajmau, India. Environ. Earth Sci. 2015, 73, 3565-3577. [CrossRef]

35. Singh, S.; Raju, N.J.; Nazneen, S. Environmental risk of heavy metal pollution and contamination sources using multivariate analysis in the soils of Varanasi environs, India. Environ. Monit. Assess. 2015, 187, 1-12. [CrossRef]

36. Zhao, L.; Xu, Y.; Hou, H.; Shangguan, Y.; Li, F. Source identification and health risk assessment of metals in urban soils around the Tanggu chemical industrial district, Tianjin, China. Sci. Total Environ. 2014, 15, 654-662. [CrossRef]

37. Karbassi, A.R.; Monavari, S.M.; Bidhendi, G.R.N.; Nouri, J.; Nematpour, K. Metal pollution assessment of sediment and water in the Shur river. Environ. Monit. Assess. 2008, 147, 107-116. [CrossRef]

38. Zhang, X.Y.; Lin, F.F.; Wong, M.T.F.; Feng, X.L.; Wang, K. Identification of soil heavy metal sources from anthropogenic activities and pollution assessment of Fuyang County, China. Environ. Monit. Assess. 2009, 154, 439-449. [CrossRef]

39. Wu, Y.G.; Xu, Y.N.; Zhang, J.H.; Hu, S.H.; Liu, K. Heavy metals pollution and the identification of their sources in soil over Xiaoqinling gold-mining region, Shaanxi, China. Environ. Earth Sci. 2011, 64, 1585-1592. [CrossRef]

40. Teng, Y.; Feng, D.; Wu, J.; Zuo, R.; Song, L.; Wang, J. Distribution, bioavailability, and potential ecological risk of $\mathrm{Cu}, \mathrm{Pb}$, and $\mathrm{Zn}$ in soil in a potential groundwater source area. Environ. Monit. Assess. 2015, 187, 293. [CrossRef]

41. Pastrana-Corral, M.A.; Wakida, F.T.; Temores-Peña, J.; Rodriguez-Mendivil, D.D.; García-Flores, E.; Piñon-Colin, T.D.J.; Quiñonez-Plaza, A. Heavy metal pollution in the soil surrounding a thermal power plant in Playas de Rosarito, Mexico. Environ. Earth Sci. 2017, 76, 583. [CrossRef]

42. Al-Khashman, O.A. The investigation of metal concentrations in street dust samples in Aqaba City, Jordan. Environ. Geochem. Health 2007, 29, 197-207. [CrossRef] [PubMed]

43. Ye, X.; Xiao, W.; Zhang, Y.; Zhao, S.; Wang, G.; Zhang, Q.; Wang, Q. Assessment of heavy metal pollution in vegetables and relationships with soil heavy metal distribution in Zhejiang Province, China. Environ. Monit. Assess. 2015, 187, 378. [CrossRef] [PubMed]

44. Liu, D.X.; Li, Y.M.; Ma, J.H.; Li, C.; Chen, X. Heavy Metal Pollution in Urban Soil from 1994 to 2012 in Kaifeng City, China. Water Air Soil Pollut. 2016, 227, 1-10. [CrossRef]

(C) 2020 by the authors. Licensee MDPI, Basel, Switzerland. This article is an open access article distributed under the terms and conditions of the Creative Commons Attribution (CC BY) license (http://creativecommons.org/licenses/by/4.0/). 